\title{
TORTÍCOLIS MUSCULAR CONGÉNITO Y DISOCIACIÓN CLÍNICO- ECOGRÁFICO EN EL RECIÉN NACIDO: REPORTE DE UN CASO
}

\author{
Custodio Olsen Quispe Condori ${ }^{1,2}$
}

\begin{abstract}
RESUMEN
El tortícolis muscular congénito es una entidad clínica conocida desde la antigüedad, se caracteriza por presentar una desviación de la cabeza con inclinación y rotación hacia el lado afecto, el mentón gira en sentido contrario; que produce a lo largo de la vida un defecto funcional importante del cuello y un defecto estético considerable. Los factores de riesgo son: obstétricos, maternos y fetales. Las manifestaciones clínicas se evidencian al nacimiento, cuyo diagnóstico se confirma con la ecografía solicitada en el transcurso de los dos primeros días de vida. A veces, la ecografía no contribuye a confirmar el diagnóstico clínico evidente. Este hecho se conoce como la disociación clínico ecográfico. El manejo del tortícolis muscular congénito debe iniciarse tan pronto como se haya hecho el diagnóstico clínico y tener presente que la ecografía es un examen auxiliar. Es importante valorar la pericia del evaluador en la toma de decisiones. Se presenta un caso de un recién nacido gemelar 1, de parto por vía vaginal, con tortícolis muscular congénito derecho y disociación clínico ecográfico, que se evidencia con las vistas e informes ecográficos; cuyo pronóstico es bueno cuando se inicia pronto el manejo fisioterapéutico. El presente trabajo realizado en el Instituto Nacional Materno Perinatal, tiene por objetivo contribuir al conocimiento médico e intercambiar experiencias en el diagnóstico precoz del tortícolis muscular congénito y la referencia oportuna a un centro especializado para su manejo correspondiente.
\end{abstract}

Palabras clave: Tortícolis muscular congénita; Músculo del esternocleidomastoideo; Distonía cervical (Fuente: DeCS BIREME).

\section{CONGENITAL MUSCULAR TORTICOLLIS AND DISSOCIATION CLINICAL- ULTRASOUND IN THE NEWBORN: CASE REPORT}

\begin{abstract}
The congenital muscular torticollis is an entity clinical known from the antiquity, is characterized by present a deviation of the head with tilt and rotation towards the side affection, the chin rotates in the opposite direction; that produces throughout her life a defect functional important of the neck and a defect aesthetic considerable.

The risk factors are: obstetric, maternal and fetal. The clinical manifestations are evident at birth, whose diagnosis is confirmed with ultrasound requested in the course of the first two days of life. Sometimes ultrasound does not contribute to confirm the clinical diagnosis evident. This fact is known as dissociation clinical ultrasound. Management of congenital muscular torticollis should start as soon as the diagnosis is made and keep in mind that the ultrasound is an auxiliary examination. It is important to assess the expertise of the evaluator in decision-making process. A case is presented of the newborn twin 1 , birth vaginally, with congenital muscular torticollis right and dissociation clinical ultrasound, which is evidenced with the views and reports ultrasound; whose prognosis is good when it starts soon the management physiotherapist. The present work realized in the Institute National Materno Perinatal, has by objective contribute to the knowledge medical e exchange experiences in the diagnosis early of the congenital muscular torticollis and it reference timely to a center specialized for its management corresponding.
\end{abstract}

Key Word: Congenital muscular torticollis; Esternocleidomastoideo muscle; Cervical distonía (Source:MeSH NLM).

\section{INTRODUCCIÓN}

El cuerpo humano posee una simetría bilateral característica (simetría axial o vertical), que consiste en que una parte del cuerpo se corresponde con la contralateral, es decir, que la parte izquierda del cuerpo es semejante a la derecha. El tortícolis muscular congénito (TMC) es una entidad clínica conocida desde la antigüedad, consistente en un acortamiento del músculo esternocleidomastoideo (ECM) asociado o no a tumoración del vientre muscular, que produce a lo largo de la vida un defecto funcional importante del cuello y un defecto estético considerable y es la tercera anomalía músculo-esquelética más frecuente, después de la luxación congénita de cadera y del pie zambo ${ }^{1,2}$ históricamente la incidencia varía de 0,3 al $2 \%$ y más recientemente reportan hasta el $16 \%$ en recién nacidos sanos ${ }^{3}$.

Factores de riesgo: obstétricos como los partos dificultosos; maternos la primiparidad, fibromiomas, oligoamnios; fetales la macrosomía fetal, embarazos múltiples Causas: el TMC de causa postural e intrauterino, es la más frecuente y es consecuencia del espacio físico intrauterino reducido del que dispone el producto asociado

Servicio de Puericultura, Departamento de Neonatología, del Instituto Nacional Materno Perinatal

2 Departamento Académico de Pediatría de la Facultad de Medicina de la UNMSM.

Recibido: 01-12-16 Aprobado: 30-12-16 
a la posición que adopta el feto por largo tiempo en el útero de la mujer embarazada, lo que provocaría la inclinación de la cabeza con un acortamiento o falta de desarrollo del músculo ECM afecto, y que no está asociado a una tumoración a lo largo del músculo ECM afecto, que se manifiesta clínicamente al nacer Manifestación clínica el cuadro clínico se caracteriza por una inclinación con rotación de la cabeza hacia el lado afecto con acortamiento del músculo ECM, con asimetría de frente, cara y cuello; en cuanto a la asimetría de la frente puede presentar leve aplanamiento oblicuo del lado no afecto; en la asimetría de cara presenta poco desarrollo de la región orbitaria, malar y del ángulo mandibular del lado afecto y en la región nasal se observa desviación del tabique nasal hacia el lado afecto con asimetría del vestíbulo de las fosas nasales; en cuanto a la asimetría del cuello se observa en el lado afecto: inclinación de la cabeza sobre el cuello, con hundimiento de la zona del músculo ECM, fosa clavicular con leve depresión, disminución de la distancia cuello-hombro, hombro ligeramente elevado. El mentón gira hacia el lado no afecto. Disminución de la movilidad activa y pasiva como la flexión, extensión y rotación de la columna cervical. Asimismo, si el cuadro clínico es de consideración, pueden producirse defectos en el crecimiento de las vértebras cervicales debido a la mal posición mantenida durante largo tiempo. No existe relación entre la severidad del cuadro clínico con el modo de nacimiento, por observarse tanto en el recién nacido (RN), de parto vaginal como de parto por cesárea. La posición lateralizada de la cabeza es lo que motiva la consulta médica ${ }^{1,4,5,6}$. Figura 1 . Diagnóstico debe incluir una exploración clínica, neurológica con el estudio ecográfico. Ecografía que ha de realizarse en el transcurso de su primer o segundo día de vida ${ }^{7}$. La ecografía es el procedimiento de elección para el estudio de los tortícolis ${ }^{4,6,7}$; pero, muchas veces las ecografías solicitadas no contribuyen al diagnóstico de tortícolis muscular congénito. Este hecho se conoce como la disociación clínico ecográfico y posiblemente su frecuencia real sea desconocida y mayor que las descritas al tratarse de una deformación infra diagnosticada. Frente a un caso de TMC con disociación clínico ecográfico, iniciar cuanto antes el manejo de tortícolis. La ecografía es un indicador paraclínico para apreciar la severidad y el pronóstico del tortícolis, algunas veces se solicita la radiografía cervical en busca de anomalías óseas y en casos seleccionados la tomografía axial computarizada y resonancia magnética nuclear 6,7 . Manejo: a cargo de los profesionales especializados en rehabilitación y fisioterapia para los ejercicios de estiramiento y movimiento del cuello como la flexión, extensión y rotación; así como, el tratamiento postural, la posición para la alimentación y educación a los padres para que vayan realizando el trabajo en casa ${ }^{8}$ Pronóstico es bueno, cuando el diagnóstico y el tratamiento son inmediatos, en casos severos puede necesitar un tratamiento quirúrgico ${ }^{5,6,7}$. El presente trabajo realizado en el Instituto Nacional Materno Perinatal tiene por Objetivo contribuir al conocimiento médico e intercambiar experiencias en el diagnóstico precoz del recién nacido con TMC de causa postural e intrauterino, con disociación clínico ecográfico y la referencia oportuna a un centro especializado para su manejo correspondiente. La madre de la RN dio su consentimiento para la presente publicación.

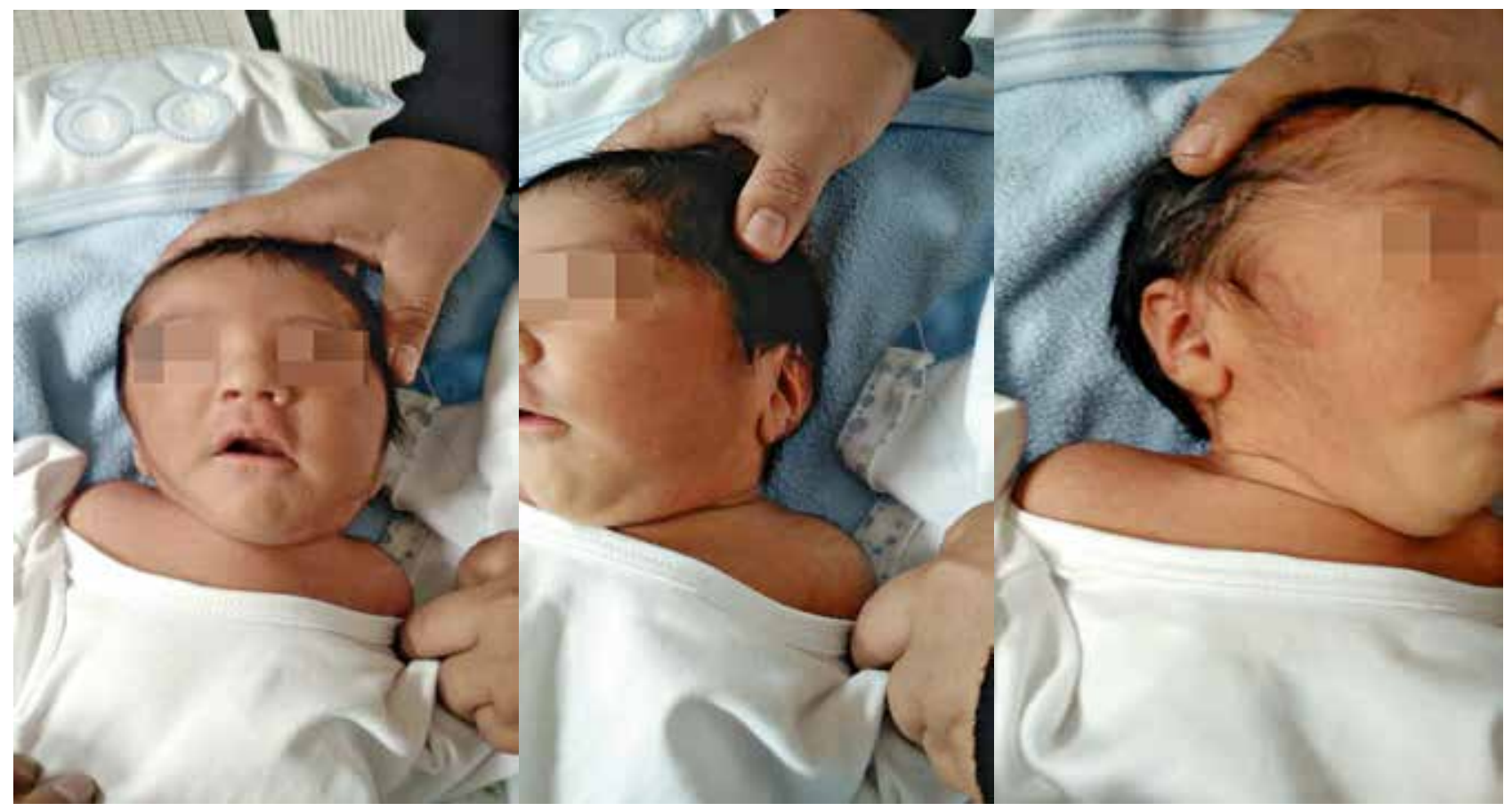

Figura 1. RN con tortícolis muscular congénito derecho.
Figura 2. RN con tortícolis muscular congénito derecho. Vista de cuello, lado no afecto.
Figura 3. RN con tortícolis muscular congénito derecho. Vista de cuello, lado afecto. 


\section{CASO CLÍNICO}

RN gemelar 1, de parto por vía vaginal, el día 10 de julio 2 016, de sexo masculino, peso $2868 \mathrm{~g}$, talla $49 \mathrm{~cm}$, perímetro cefálico $35,5 \mathrm{~cm}$, perímetro torácico de $31,5 \mathrm{~cm}$, Apgar normal. Líquido amniótico meconial fluido. Datos de la madre: edad 36 años, G4P2012, un aborto hace dos años, control prenatal seis veces, Peso preconcepcional $65 \mathrm{~kg}$, peso momentos antes del parto $80 \mathrm{~kg}$, talla $165 \mathrm{~cm}$. Análisis laboratoriales, Presión arterial y Temperatura dentro de los valores referenciales. Ecografía obstétrica de 06 de julio 2 016: gestación múltiple de 36 semanas 4 días por biometría promedio, ambos fetos en cefálico, Diagnóstico: gestante 4, de 38 semanas por última regla, trabajo de parto fase activa.

Examen físico al nacer: buen estado general con examen físico normal y con indicaciones de pasar a alojamiento conjunto con lactancia materna exclusiva. A las 26 horas de vida se realiza la visita médica al neonato, encontrándose al examen preferencial la inclinación de la cabeza hacia el lado derecho, impresiona cuello corto, se observan asimetría de cara y de cuello. En cuanto a la asimetría facial: se encuentra la región orbitaria y malar del lado derecho afectado en su desarrollo; asimismo, se observa el compromiso del desarrollo del ángulo mandibular derecho, comparado con el lado izquierdo. En cuanto a la asimetría del cuello: se observa inclinación con ligera rotación de la cabeza sobre el lado derecho con hundimiento de la zona del músculo ECM derecho, disminución de la distancia cuello-hombro del lado derecho, mentón lateralizado hacia el lado izquierdo, fosa clavicular derecha con leve depresión, hombro derecho ligeramente elevado y disminución de la movilidad activa y pasiva de la columna cervical. Figuras 1 , 2,3. Impresión diagnóstica: Tortícolis muscular congénito derecho de causa postural e intrauterino. Indicación: solicitud de ecografía de cuello de partes blandas, a fin de corroborar el diagnóstico clínico.

Visita médica a las 50 horas de vida, clínicamente estable, aun no le toman la ecografía de cuello.

Visita médica a las 74 horas de vida, clínicamente estable. A las 78 horas de vida llega el INFORME ECOGRÁFICO 450250 de 12/072016: ECOGRAFÍADEPARTESBLANDAS DE REGIÓN CERVICAL: músculo esternocleidomastoideo derecho $4,9 \mathrm{~mm}$ de espesor, ecogenecidad conservada y patrón fibrilar. músculo esternocleidomastoideo izquierdo 45,6 mm de espesor ecogenecidad conservada y patrón fibrilar. Conclusiones: no se encuentra imágenes en relación a torticolis congénita. Figura 4.

A las 79 horas de nacido, se vuelve a solicitar otra ecografía de cuello con otro médico ecografista, cuyo informe es: Esternocleidomastoideo derecho: AP 3,7 mm, T 13,1 mm. Esterno cleidomastoideo izquierdo: AP 5,2mm, T 17,0 $\mathrm{mm}$, conclusión: asimetría de tamaño y ecogenecidad de ambos esternocleidomastoideos. Figura 5.

Diagnósticos: RN de término de 38 semanas. Adecuado para la Edad Gestacional. RN de parto eutócico, gemelar

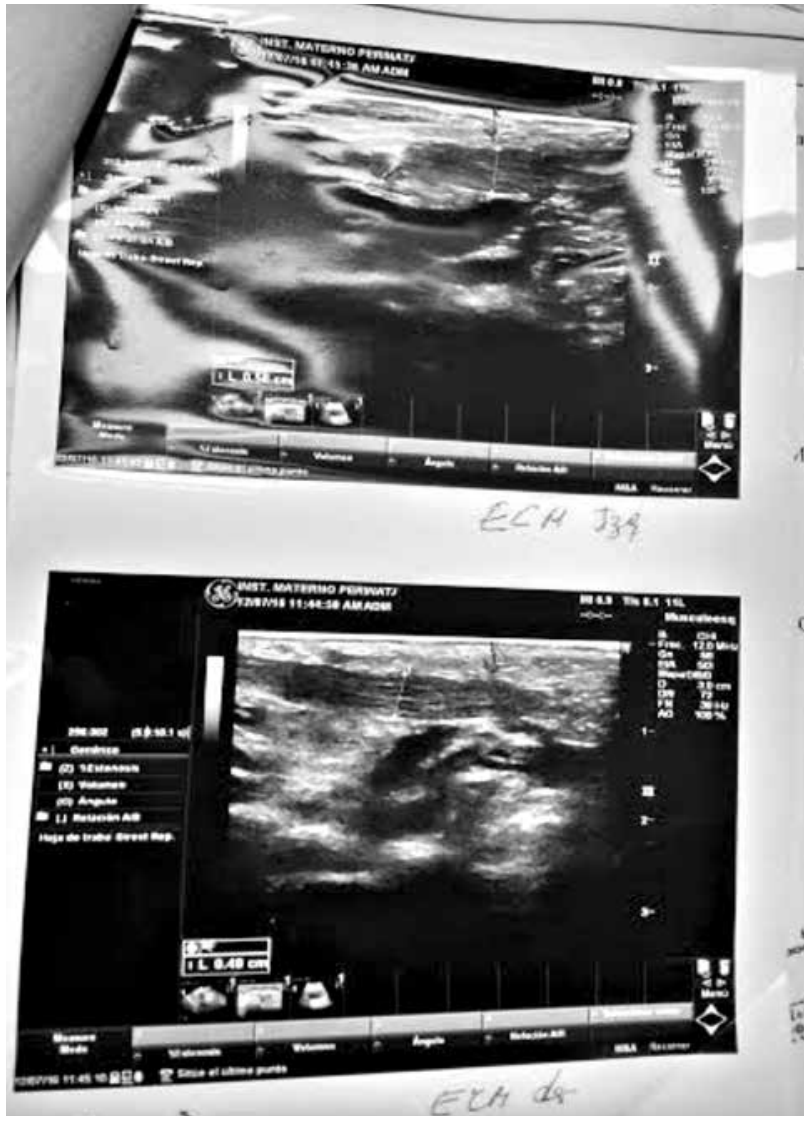

Figura 4. Primera ecografía de cuello, tomada el día 1207-2016

1. Tortícolis muscular congénito derecha de causa postural e intrauterino con disociación clínico ecográfico.

Informe de ecografía de partes blandas de región cervical: Músculo esternocleidomastoideo derecho $4,9 \mathrm{~mm}$ de espesor, ecogenecidad conservada y patrón fibrilar. Músculo esternocleidomastoideo izquierdo: $45.6 \mathrm{~mm}$ de espesor, ecogenecidad conservada y patrón fibrilar. Conclusiones: no se encuentra imágenes en relación a tortícolis congénita.

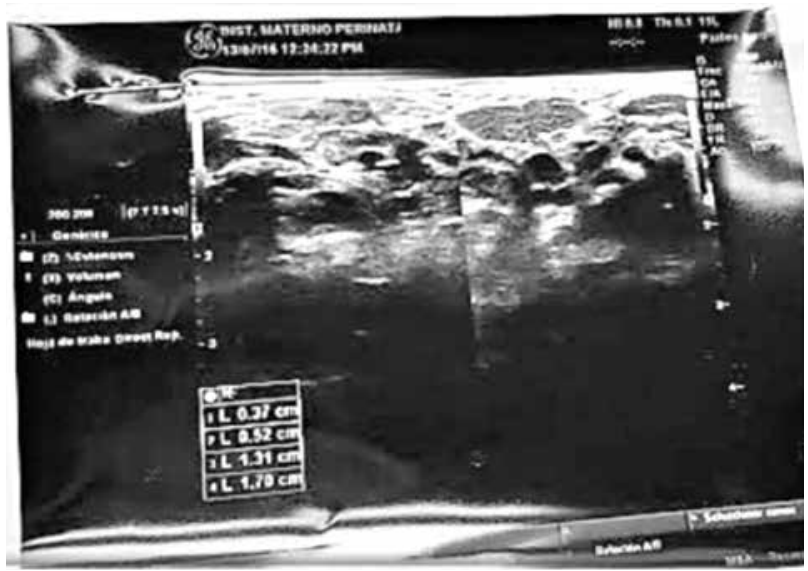

Figura 5. Segunda ecografía de cuello, tomada el día 1307-2016 
Informe ecográfico del día 13-07-2016.

Esternocleidomastoideo derecho AP: $3.7 \mathrm{~mm}$ T: $13.1 \mathrm{~mm}$ Esternocleidomastoideo izquierdo: AP: $5.2 \mathrm{~mm}$ T: 17.0 $\mathrm{mm}$ Conclusión: asimetría de tamaño y ecogenecidad de ambos esternocleidomastoideos.

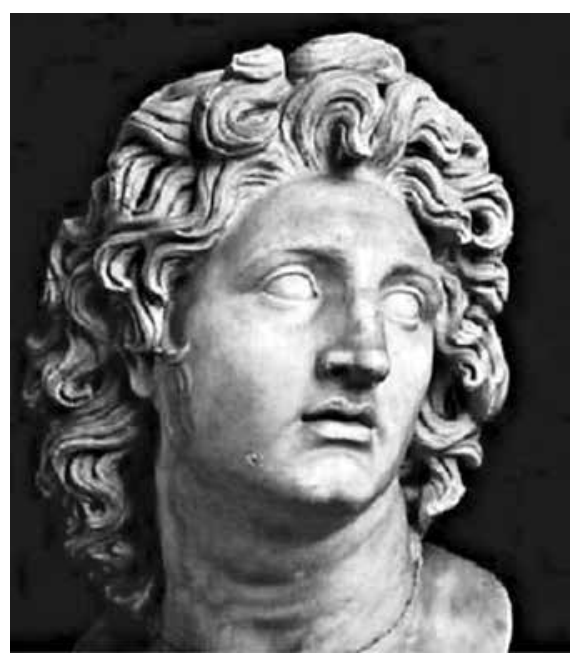

Figura 6. Secuela de tortícolis

\section{DISCUSIÓN}

EI TMC de causa postural e intrauterino es una alteración músculo esquelético benigno que con frecuencia, se asocia a otras anomalías ortopédicas ${ }^{(1,5,7}$. El sitio anatómico de la enfermedad regularmente está confinado al vientre del músculo ECM. Figura 1,2 y 3 . En el RN, como en el presente caso, lo que llama más la atención en el examen físico a la inspección es la inclinación anormal de la cabeza sobre el lado derecho del cuello, con hundimiento de la zona o vientre del músculo ECM derecho. El primer informe ecográfico describe la diferencia en el espesor de los músculos esternocleidomastoideos, siendo el lado derecho menor que el lado izquierdo; pero en la conclusión refiere no encontrar imágenes en relación a tortícolis congénita Figura 4. En cambio, en el segundo informe ecográfico describe las diferencias en las dimensiones anteroposterior y transverso, concluyendo una asimetría del tamaño y ecogenecidad de ambos esternocleidomastoideos, siendo el lado derecho menor que el lado izquierdo Figura 5. Como se puede ver los informes ecográficos no son congruentes; pero en ambos informes describen las diferencias de las dimensiones de los músculos esternocleidomastoideos, siendo menor las dimensiones en el músculo ECM derecho, el cual es congruente con el hallazgo clínico. En el presente caso la conclusión del primer informe ecográfico no contribuye al diagnóstico clínico evidente de torticolis muscular congénito derecho, es decir, existe la disociación clínico ecográfico. Para tal diagnóstico interviene la pericia del que explora al recién nacido, a fin de referir cuanto antes a un centro especializado como el Instituto Nacional de Rehabilitación para el manejo correspondiente y evitar las secuelas. Figura 6.

Presentamos el caso por tratarse de un RN gemelar 1, con TMC derecha de causa postural e intrauterino con disociación clínico ecográfico.

\section{REFERENCIAS BIBLIOGRÁFICAS}

1. Lacruz-Rengel MA, Romero A, Márquez-Albornoz C, Rojas de Hernández M. Características clínicas y evolutivas del tortícolis muscular congénito. Arch Venez Puer Ped. Caracas mar.2013; 76 (1):12-16.

2. Tomczak KK, Rosman NP. Torticollis. Journal Child Neurol 2013; 28: 365-378.

3. Suhr M, Oledzka. Considerations and intervention in congenital muscular torticollis. Curr Opin Pediatr 2015; 27(1): 75-81.

4. Watemberg N, Ben-Sasson A, Goldfarb R. Transient Motor Asymmetry Among

Infants With Congenital Torticollis-Description, Characterization, and Results of Follow-Up. Pediatric Neurology 2016; 59:36-34.

5. Quispe C, Carmen Del Carmen. Torticollis muscular congénito de causa postural e intrauterino: reporte de un caso. Rev Peru Investing Materno Perinat 2015; 4(1): 69-72.

6. Kuo A, Tritasavit $S$ and Graham J. Congenital Muscular Torticollis and Positional Plagiocephaly. Pediatrics in Review 2014; Vol 35 N²:79-86.

7. American Physical Therapy Association. Congenital Muscular Torticollis Practice Guidelines 351. Pediatr Phys Ther 2013; 25:348-394.

8. Genna CW. Breastfeeding infants with Congenital Torticollis. Journal of Human Lactation 2015; vol 31(2):216-220.

Correspondencia: Custodio Olsen Quispe Condori Dirección: Jirón Juan Bujanda $N^{\circ} 335$, Departamento $N^{\circ} 504$, Urbanización Montecarmelo, Lima 13, Perú.

Correo-e: custodioolsen@hotmail.com 